\title{
Are patients on oral anticoagulation therapy aware of its effects? A cross-sectional study from Karachi, Pakistan
}

\author{
Ibrahim Zahid ${ }^{1 *}$ (D), Syed Wajih UI Hassan², Nida Sehar Bhurya², Sheena Nadeem Alam², \\ Choudhary Ahmed Hasan', Bakht Hussain Shah', Fasiha Bakhtawar Fatima', Ayesha Ahmed², \\ Syed Sabih UI Hassan', Javeria Hayat ', Aqsa Zulfiqar², Rija Sheikh², Momin Aziz', Rabbia Siddiqi', \\ Kaneez Fatima ${ }^{1}$ and Muhammad Shahzeb Khan ${ }^{3}$
}

\begin{abstract}
Objective: Oral anticoagulants are one of the most frequently used medications. However, these drugs have a range of side effects including potential life-threatening complications. Little is known regarding the awareness of its side effect profile amongst the patients in Pakistan. Therefore, the aim of this study was to assess the knowledge of oral anticoagulant therapy and its side effects among its users.

Results: The mean age was $48.9 \pm 15.2$ years. Median scores of the participants for knowledge regarding oral anticoagulants and warfarin were 48.7 (8.3-91.7) and 10.3 (0.0-70.0) respectively. Of 207 patients, most notably, 65.7\% did not know what side effects to be wary of or how to reduce their occurrence; and most patients were unaware of the interaction between oral anticoagulant drugs and over-the-counter substances such as aspirin, herbal medicines and alcohol. Knowledge of international normalised ratio (INR) was extremely poor with more than $75 \%$ of the population not being aware of the target INR range during warfarin therapy. Higher level of education was significantly associated with better knowledge scores. Overall, knowledge of oral anticoagulant therapy and INR monitoring is extremely poor among oral anticoagulant users.
\end{abstract}

Keywords: Anticoagulants, Warfarin, International normalised ratio

\section{Introduction}

With several indications ranging from atrial fibrillation to mechanical heart valves, oral anticoagulants (OAC) use is quite pervasive in modern society $[1,2]$. Drugs like warfarin and apixaban impede clotting of blood and hence are used where there is a high risk of thrombosis. However, OAC especially warfarin, have a narrow therapeutic index which requires careful dosing and monitoring to avoid both ineffectual doses and side effects [3]. Side

\footnotetext{
*Correspondence: ibrahim_zahid@hotmail.com

${ }^{1}$ Dow Medical College, Dow University of Health Sciences, Karachi,

Pakistan

Full list of author information is available at the end of the article
}

effects include, but are not limited to, bleeding diatheses, thromboembolism, and hypersensitivity reactions [4].

Despite the prevalence of their use and risk of serious adverse effects, several studies have shown that most patients do not have adequate knowledge of the OAC they are using $[5,6]$. Other studies have found that longterm outcomes of OAC are better when patients possess greater knowledge regarding OAC medications [7, 8]. The improved outcome has been attributed to several factors such as increased adherence to dosing schedules, regulation of diet to prevent interactions with the anticoagulants, and closer monitoring of the side effects of anticoagulation therapy. Meanwhile, awareness of Internal Normalised Ratio (INR) monitoring is equally important

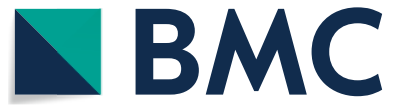

(c) The Author(s) 2020. This article is licensed under a Creative Commons Attribution 4.0 International License, which permits use, sharing, adaptation, distribution and reproduction in any medium or format, as long as you give appropriate credit to the original author(s) and the source, provide a link to the Creative Commons licence, and indicate if changes were made. The images or other third party material in this article are included in the article's Creative Commons licence, unless indicated otherwise in a credit line to the material. If material is not included in the article's Creative Commons licence and your intended use is not permitted by statutory regulation or exceeds the permitted use, you will need to obtain permission directly from the copyright holder. To view a copy of this licence, visit http://creativeco mmons.org/licenses/by/4.0/. The Creative Commons Public Domain Dedication waiver (http://creativecommons.org/publicdomain/ zero/1.0/) applies to the data made available in this article, unless otherwise stated in a credit line to the data. 
for improved outcomes. Previous studies have shown a positive correlation between the knowledge of patients' warfarin therapy and the INR values lying within the target ranges [8,9]. Poor treatment outcomes were seen in patients with lack of medication adherence and knowledge deficits [9]. Data particularly regarding knowledge of OAC is highly insufficient in Pakistan; upon assessing the frequency of achieving target INR during warfarin therapy, a study from 2012 revealed poor monitoring and control without precisely identifying the reason behind it [10]. Considering the scarcity of relevant data in Pakistan, our study specifically aims to assess the level of knowledge patients have about their OAC.

\section{Main text Methods}

This quantitative, multi-centric, cross-sectional study was conducted from January to June 2019 at Civil Hospital Karachi and National Institute of Cardiovascular Diseases, Karachi Pakistan. Ethical approval was obtained from Institutional Review Board of Dow University of Health Sciences, Pakistan.

Patients taking any OAC drugs for at least 1 month were included in the study through non-probability convenience sampling except paediatric patients, medical staff, nurses, medical students, healthcare professionals and those unwilling to participate. A written informed consent was taken from the patients, stating the aim of the study and its impact; confidentiality of patients was ensured. Based on the assumption that $74.1 \%$ had adequate knowledge regarding $\mathrm{OAC}[11]$, and taking a $5 \%$ margin of error and $90 \%$ confidence level, the calculated sample size was 207. After adjusting for $10 \%$ nonresponse (or partially filled forms), 230 patients were recruited for the study.

Face-to-face interviews were conducted with the patients using the Oral Anticoagulation Knowledge Tool (AKT) which was shown to have acceptable validity and reliability in a previous study [12]. The questionnaire is divided into three parts (see Additional file 1: Appendix S1). The first section is related to the demographic characteristics of patients. The second part consisted of 20 questions to assess the patients knowledge about OAC (section 2), and the final 8 questions (section 3) were exclusive to patients on warfarin therapy.

For each question, ' 1 ' mark was awarded for each correct answer and ' 0 ' for each wrong answer, except for questions ' 18 ' and ' 19 ' in 'section 2 ' and ' $6 \mathrm{~b}$ ' in 'section 3'. In these questions 1 mark was given for each correct point out of 3 . Section 2 was scored out of 24 , and section $B$, which was only filled by patients on warfarin therapy, was scored out of 10 . Final scores were presented as a percentage of correct answers for all the participants in the study. A cut off of $>50 \%$ was considered as an adequate knowledge score.

Data were analyzed using IBM Statistical Package for the Social Sciences (SPSS) version 22. Knowledge of OAC was evaluated through total oral AKT scores by simply counting the number of correct answers and calculating their percentages. Frequencies and percentages were calculated for all categorical variables. Overall mean and median scores were calculated for both sections, and mean scores of both sections were also reported for all demographic groups. Mann-Whitney U Test (for 2 groups) and Kruskal-Wallis Test (for more than 2 groups) were applied to compare mean scores among different demographic characteristics. $p<0.1$ was considered to be significant.

\section{Results}

The study had a response rate of $90 \%$. As presented in Table 1, the mean age was $48.9 \pm 15.2$. Half of the study population was male $(n=105 ; 50.7 \%)$. Most of the participants $(\mathrm{n}=138 ; 66.7 \%)$ had no formal education and almost half $(\mathrm{n}=98 ; 47.3 \%)$ had a monthly family income of $\$ 100-200$.

When assessed for knowledge, most of the participants were using warfarin $(\mathrm{n}=147 ; 71 \%)$, and about one-quarter were taking rivaroxaban $(\mathrm{n}=45 ; 21.7 \%)$. Most patients $(n=116 ; 56.1 \%)$ knew that these drugs actually prevent blood from clotting but more than a quarter of the participants did not know the drug mechanism $(n=66$; $31.9 \%$ ). More than half the patients said it is important to take medicine same time each day $(\mathrm{n}=139 ; 67.1 \%)$ and $64.7 \%(\mathrm{n}=134)$ disagreed to double the dose if missed. Nearly half of the study population believed that missing a dose could worsen their condition $(n=87 ; 42 \%)$. Majority of patients believed that they should continue with the drug even if they felt better $(n=111 ; 53.6 \%)$. Majority was unsure if it is safe to take anti-inflammatory drugs or vitamins, herbal medicines or alcohol with their OAC.

There was a positive response from the patients regarding informing their physician or dentist about their OAC $(\mathrm{n}=161 ; 77.8 \%)$. Most patients were unaware about main side effects of their anticoagulant or over all three side effects to watch out for $(\mathrm{n}=113 ; 54.6 \%)$. When patients were asked about the best step if they consume too much of this medicine, most of them opted for consulting their doctor $(n=110 ; 53.2 \%)$. This is displayed in Table 2.

Table 3 shows knowledge of participants specific to warfarin therapy. More than three-quarters of the study population $(\mathrm{n}=116 ; 78.9 \%)$ did not know about the target INR range during warfarin therapy. Most of the patients were unware of their last INR reading $(n=78$; $53.1 \%)$. Only $16.4 \%$ believed that regular INR tests were 
Table 1 Demographics of study population and mean scores

\begin{tabular}{|c|c|c|c|c|c|}
\hline \multirow[t]{2}{*}{ Demographics } & \multirow{2}{*}{$\begin{array}{l}\text { Frequency } \\
\mathrm{n}(\%)\end{array}$} & \multicolumn{4}{|c|}{ Mean percentage score $\pm S D$} \\
\hline & & $\begin{array}{l}\text { Knowledge } \\
\text { of anticoagulant }\end{array}$ & P-value & $\begin{array}{l}\text { Knowledge specific } \\
\text { to warfarin }\end{array}$ & P-value \\
\hline Age groups (years) & & & 0.452 & & 0.277 \\
\hline Mean \pm SD (years) & $48.9 \pm 15.2$ & & & & \\
\hline$\leq 30$ & $27(13.0)$ & $46.5 \pm 16.3$ & & $16.5 \pm 13.4$ & \\
\hline $31-50$ & $92(44.4)$ & $50.1 \pm 16.9$ & & $13.2 \pm 16.9$ & \\
\hline$>50$ & $88(42.5)$ & $50.6 \pm 15.5$ & & $15.4 \pm 16.9$ & \\
\hline Gender & & & $0.055^{*}$ & & 0.185 \\
\hline Male & $105(50.1)$ & $51.9 \pm 16.8$ & & $13.3 \pm 16.8$ & \\
\hline Female & $102(49.3)$ & $47.7 \pm 15.4$ & & $15.7 \pm 16.0$ & \\
\hline Marital status & & & 0.666 & & 0.366 \\
\hline Single & $38(18.4)$ & $48.2 \pm 15.1$ & & $15.8 \pm 14.8$ & \\
\hline Married & $169(81.6)$ & $50.2 \pm 16.4$ & & $14.2 \pm 16.8$ & \\
\hline Highest level of education & & & $<0.001^{*}$ & & 0.977 \\
\hline High school or equivalent & $56(27.1)$ & $56.7 \pm 16.3$ & & $16.2 \pm 20.4$ & \\
\hline Technical or vocational education & $5(2.4)$ & $56.7 \pm 11.3$ & & $12.5 \pm 9.6$ & \\
\hline Bachelor's and above & $8(3.9)$ & $60.4 \pm 19.9$ & & $18.3 \pm 24.8$ & \\
\hline No formal education & $138(66.7)$ & $46.2 \pm 15.0$ & & $13.6 \pm 13.6$ & \\
\hline Occupation & & & 0.228 & & 0.434 \\
\hline Service and sales worker & $9(4.4)$ & $53.2 \pm 16.8$ & & $11.7 \pm 16.0$ & \\
\hline Skilled agricultural, forestry and fishery workers & $6(2.9)$ & $38.9 \pm 5.0$ & & $12.5 \pm 18.9$ & \\
\hline Craft and related trades workers & $12(5.8)$ & $54.2 \pm 15.2$ & & $12.9 \pm 14.9$ & \\
\hline Plant and machine operators and assemblers & $10(4.8)$ & $54.2 \pm 13.6$ & & $14.3 \pm 19.0$ & \\
\hline Elementary occupations & $33(15.9)$ & $52.3 \pm 16.3$ & & $9.6 \pm 16.5$ & \\
\hline Housewife & $84(40.6)$ & $47.6 \pm 15.7$ & & $15.9 \pm 16.7$ & \\
\hline Unemployed/retired & $40(19.3)$ & $48.6 \pm 16.0$ & & $15.9 \pm 13.4$ & \\
\hline $\begin{array}{l}\text { Managers/professionals/technicians and associate } \\
\text { professionals }\end{array}$ & $13(6.3)$ & $57.4 \pm 21.7$ & & $18.3 \pm 21.2$ & \\
\hline Family income (USD) & & & 0.182 & & $0.032^{*}$ \\
\hline$<100$ & $80(38.6)$ & $48.9 \pm 17.6$ & & $17.5 \pm 15.6$ & \\
\hline $100-200$ & $98(47.3)$ & $48.5 \pm 13.7$ & & $13.4 \pm 15.6$ & \\
\hline $200-500$ & 26 (12.6) & $56.6 \pm 18.1$ & & $10.5 \pm 19.4$ & \\
\hline$>500$ & $3(1.5)$ & $61.1 \pm 26.7$ & & $20.0 \pm 26.5$ & \\
\hline
\end{tabular}

*Significant at $10 \%$ level

necessary to know if the medicine is working. More than half of the participants $(\mathrm{n}=98 ; 66.7 \%)$ were not sure if diet had any effect on their warfarin therapy, and a fairly small percentage agreed to this idea $(n=24$; $16.3 \%)$.

Additional file 2: Table S1 further elaborates on the mean knowledge scores of the population. Only $41.5 \%$ of people had good knowledge and were able to score above $50 \%$ mark when assessed for knowledge about their OAC, and less than $2 \%$ were above this mark when assessed for knowledge specific to warfarin. Upon assessing knowledge scores according to the demographic characteristics, male gender and having a minimum of bachelors level education was significantly related to higher anticoagulant knowledge scores; monthly income greater than USD 500 was associated with higher knowledge of warfarin, as shown in Table 1.

\section{Discussion}

Similar to researches conducted by Shrestha et al. [5], $\mathrm{Hu}$ et al. [13] and Baker et al. [11], our study showed that patients have low knowledge towards their prescribed OAC. Taking the demographics into account, one can reasonably attribute the lack of formal education and a language barrier as the primary causes of this gap in knowledge. However, previous literature regarding the association of knowledge with age has mixed findings. Some researchers conclude that participants 
Table 2 Knowledge of OAC

Knowledge questions

Frequency

n (\%)

Name of OAC

Warfarin

$147(71)$

Rivaroxaban

$45(21.7)$

Don't know the name

$15(7.2)$

Why has your doctor prescribed this medicine

Arrhythmias

$14(6.8)$

Blood thinning

$47(22.7)$

Cardiac issue/chest pain

$20(9.7)$

DVT

$15(7.2)$

$\mathrm{Ml}$

$39(18.8)$

Prosthetic valve

$26(12.6)$

Don't know

$26(12.6)$

Others

How does this medicine work in your body

Lowers BP

Prevents blood from clotting

Lowers heart rate

Don't know

How many times a day do you need to take this medicine

Once

Twice

Thrice

Don't know

For how long do you need to take this medicine

3 months

$15(7.2)$

6 months

$18(8.7)$

1 year

$19(9.2)$

Lifelong

Don't know

Why is it important to take this medicine exactly as the doctor has told you

Too much of this can cause bleeding

Skipping a dose can cause bleeding

It interacts with food, so changing the dose/timing can be hazardous

Don't know

Is it important to take this medicine at the same time each day

Yes

No

Not sure

Is it okay to double the next dose of this medicine if you missed a dose

Yes

No

Not sure

Could missing one dose worsen your condition

Yes

No

Not sure

Is it appropriate to stop taking this medicine once you feel better 
Table 2 (continued)

Knowledge questions

Frequency

n (\%)

Not sure

Is it safe to take anti-inflammatory meds while on OAC

Yes

$67(32.4)$

No

$41(19.8)$

Not sure

$99(47.8)$

Is it safe to take vitamins, herbal meds without consulting doctor

Yes

$66(31.9)$

No

64 (30.9)

Not sure

$77(37.2)$

Is it beneficial to take more medicine than prescribed

Yes

$11(5.3)$

No

Not sure

$70(33.8)$

Will drinking too much alcohol increase the risks of this med

Yes

No

Not sure

$127(61.4)$

Would you inform surgeon, dentist, doc about your meds

Yes

$161(77.8)$

No

Not sure

27 (13)

Is it imp that all healthcare practitioners know about this med

Yes

$161(77.8)$

No

Not sure

$23(11.1)$

Most important side effect of this medicine

Bleeding

$49(23.7)$

Others

$20(9.7)$

Don't know

$136(65.7)$

Correct side effects identified

All three

Two correct

$22(10.6)$

One correct

$7(3.4)$

None

Don't know

$117(56.5)$

Side effect identified

Bleeding gums

$72(19.7)$

Prolonged nosebleeds

$50(13.7)$

Severe bruising

$32(8.8)$

Blood in urine

$64(17.5)$

Insomnia

$10(2.7)$

Loss of apetite

Don't know

How to reduce side effects

Monitor INR regularly

Monitor

$44(14.4)$

Sleeping on time

$21(6.9)$

Eating less food

$14(4.6)$

Avoid things that could cause cuts/injuries

$31(10.1)$ 
Table 2 (continued)

\begin{tabular}{lr}
\hline Knowledge questions & $\begin{array}{c}\text { Frequency } \\
\mathbf{n}(\%)\end{array}$ \\
\hline Proper dosing & $53(17.3)$ \\
Don't know & $128(41.8)$ \\
Best step if you take too much of this medicine & $35(16.9)$ \\
Skip the next dose & $110(53.1)$ \\
Consult my doctor & $15(7.2)$ \\
Be alert for signs of side effects & $47(22.7)$ \\
Don't know & \\
\hline
\end{tabular}

OAC oral anticoagulants, INR international normalized ratio

Table 3 Knowledge specific to Warfarin therapy $(n=147)$

\begin{tabular}{|c|c|}
\hline & $\begin{array}{l}\text { Frequency } \\
\text { n (\%) }\end{array}$ \\
\hline \multicolumn{2}{|c|}{ What is your target INR range } \\
\hline$<1.0$ & $17(11.6)$ \\
\hline 1.0 to 1.9 & $5(3.4)$ \\
\hline $2.0-3.0$ & $9(6.1)$ \\
\hline Don't know & $116(78.9)$ \\
\hline \multicolumn{2}{|c|}{ Last INR reading } \\
\hline$<1.0$ & $1(0.7)$ \\
\hline $1.0-2.0$ & $49(33.3)$ \\
\hline $2.1-3.0$ & $14(9.5)$ \\
\hline$>3.0$ & $5(3.4)$ \\
\hline Don't know & $78(53.1)$ \\
\hline \multicolumn{2}{|c|}{ Are regular INR tests necessary to know that the medicine is working } \\
\hline Yes & $34(23.1)$ \\
\hline No & $8(5.4)$ \\
\hline Not sure & $105(71.4)$ \\
\hline \multicolumn{2}{|c|}{ Is an INR above target good for health } \\
\hline Yes & $8(5.4)$ \\
\hline No & $20(13.6)$ \\
\hline Not sure & $119(81.0)$ \\
\hline \multicolumn{2}{|c|}{ Is an INR below target bad for health } \\
\hline Yes & $16(10.9)$ \\
\hline No & $10(6.8)$ \\
\hline Not sure & $121(82.3)$ \\
\hline \multicolumn{2}{|c|}{ Is it possible what you eat to affect your Warfarin therapy } \\
\hline Yes & $24(16.3)$ \\
\hline No & $25(17.0)$ \\
\hline Not sure & $98(66.7)$ \\
\hline \multicolumn{2}{|c|}{ Vitamins that can affect your OAC therapy } \\
\hline Vitamin A & $1(0.7)$ \\
\hline Vitamin B & $5(3.4)$ \\
\hline Vitamin $\mathrm{K}$ & $6(4.1)$ \\
\hline Don't know & $131(89.1)$ \\
\hline Others & $4(2.7)$ \\
\hline
\end{tabular}

of younger age and higher level of education scored better $[14,15]$, whereas others showed older age to positively influence the scores [16]. Our study does not show any significant relationship of knowledge scores with participants' age.

Findings of our study indicate that only $27.1 \%$ of the participants correctly identified bleeding as the most important side effect of this medication, particularly bleeding from gums, prolonged nosebleeds and blood in urine. The majority of the sample $(65.7 \%)$ did not know what side effects to be wary of or how to reduce their risk. These findings prove to be an alarming indicator of lack of knowledge as most of these participants had been asked to continue this medicine for life and their lack of knowledge about possible side effects is concerning. This gap in knowledge is common in reference to many studies, one of which reported only $42 \%$ of their sample population to be aware of any possible side effects of warfarin therapy [17].

Another particular area of concern was the inadequate patient understanding of warfarin's interactions. Majority of the participants were unaware of the interaction of OAC drugs with over the counter pills like aspirin, herbal medicines and alcohol. Drugs such as Non-Steroidal Anti-Inflammatory Drugs (NSAIDs) and aspirin inhibit platelet function therefore when used with oral anticoagulants, they may increase the risk of bleeding [18]. There is a high prevalence of multiple NSAIDs prescription in Pakistan [19], an alarming fact when considering that NSAIDs increase the risk of gastrointestinal bleeding when used in combination with warfarin, and that only a minority of our sample was aware of this interaction. Alcohol, on the other hand, interacts with the cytochrome P450 system, responsible for metabolizing warfarin. Only one-third of the study population understood the risk of concurrent use of alcohol and an even smaller percentage to that with NSAIDs. A similar finding was obtained by Shrestha et al. [5], who reported that $94.1 \%$ of their sample did

INR international normalized ratio 
not know which drinks could decrease warfarin's effectiveness. This is particularly worrying when taking into consideration the fact that excess alcohol can increase the risk of major bleeding when taken with warfarin, and only $23.7 \%$ of our sample could identify bleeding as the most important side effect of oral anticoagulants. These findings were similar to results obtained by Roche et al. [6], Yahaya et al. [20] and Campbell et al. [21]. A lack of understanding with regards to dietary restrictions was also evident. A majority of the study population did not consider vitamin supplementation or the use of vegetables, such as kale or spinach, deleterious to their warfarin therapy; a finding consistent with a study conducted by Nasser et al. [22].

The sample population barely knew about INR, its target values and the importance of therapeutic INR range; attaining a mean score of only $14.6( \pm 16.4) \%$. Furthermore, a research also found that even though young and educated people are likely to have better knowledge about their anticoagulant medicines, this does not affect their INR control or episodes of bleeding and/or thrombosis [23]. On the contrary, a research in Saudi Arabia showed INR control to be positively influenced by knowledge about their OAC [24]. Maintaining a stable INR is an important indicator of adequate anticoagulation in the body, because supratherapeutic value increases the probability of bleeds and subtherapeutic value may cause thrombosis [25]. Within our sample population, the ability to self-monitor is likely to be reduced due to their lack of adequate knowledge about INR, increasing the probability of patients being under or over treated.

A positive result identified in our patient population indicated that over three quarters of people agreed it was important for their healthcare providers to know they were taking an $\mathrm{OAC}$, and the similar proportion of people said that they would usually inform their doctors about their drug history. In contrast, Khudair et al. [26] found that most participants did not know the importance of informing healthcare professionals if they were on warfarin.

\section{Recommendations}

One way to fill this knowledge gap is to ensure that patients receive proper counselling whenever they are prescribed a new drug, and at regular intervals thereafter. Healthcare providers should allocate more time to counselling their patients, focusing on drug side effects and interactions, as well as the proper course of action to take once adverse effects occur. Pamphlets with information on the prescribed drug should also be provided to patients, giving them a chance to refresh their knowledge at their own convenience. More emphasis should also be placed on the need for INR monitoring after beginning warfarin therapy, as this is one area where patient knowledge is severely lacking. Considering the high risk profile of the drugs, follow ups with the patients should involve inquiring from and educating them about the potential effects to serve as reinforcement.

\section{Conclusions}

The findings show that majority of the patients have poor level of knowledge about oral anticoagulant therapy and knowledge about INR monitoring with warfarin therapy is highly substandard.

\section{Limitations}

The study only included 207 participants and a larger sample size from different hospital settings is required to generalize the findings. Most patients were admitted in government hospitals, with little data obtained from private setups, and the majority of our sample population belonged to a low socioeconomic background and received little to no formal education, which could influence the results. There is a need for inclusion of moderate-high socioeconomic patients and patient with higher educational background in further studies in Pakistan. Second, the data was not divided according to the hospital it was collected from. This could have provided us with some insight into the effectiveness of patient counseling in the different setups. Furthermore, our questionnaire did not assess level of knowledge with duration of therapy or calculate a passing rate for the proportion of people with adequate knowledge.

\section{Supplementary information}

Supplementary information accompanies this paper at https://doi. org/10.1186/s13104-020-05119-w.

Additional file 1: Appendix S1. Anticoagulant knowledge tool.

Additional file 2: Table S1. Knowledge scores.

Abbreviations

OAC: Oral anti coagulant; INR: International normalised ratio; AKT: Anticoagulation knowledge tool; NSAIDs: Non-steroidal anti-inflammatory drugs.

\section{Acknowledgements}

Not applicable.

\section{Authors' contributions}

IZ, RaS, KF and MSK were involved in study design. IZ, BHS, FBF and CAH were involved in data analysis. IZ, SWUH, NSB, SNA, BHS, FBF, CAH, AA, SSUH, JH, AZ, $\mathrm{RS}$ and MA performed data collection, article writing and compilation of the manuscript. All the authors contributed to article writing. All authors reviewed the final manuscript. All authors read and approved the final manuscript.

\section{Funding}

None. 


\section{Availability of data and materials}

The datasets used and/or analyzed during the current study are available from the corresponding author on reasonable request.

\section{Ethics approval and consent to participate}

The study was approved by the Ethical Review Committee of Dow University of Health Sciences, Pakistan and written informed consent was taken from each participant prior to data collection.

\section{Consent for publication}

Informed consent was obtained from the study participants for publication of data.

\section{Competing interests}

The authors declare that they have no competing interests.

\section{Author details}

${ }^{1}$ Dow Medical College, Dow University of Health Sciences, Karachi, Pakistan.

${ }^{2}$ Dr. Ruth K.M. Pfau Civil Hospital, Karachi, Pakistan. ${ }^{3}$ John H Stroger Jr. Hospital of Cook County, Chicago, IL, USA.

Received: 3 April 2020 Accepted: 27 May 2020

Published online: 09 June 2020

\section{References}

1. DiPiro JT, Talbert RL, Yee GC, Matzke GR, Wells BG, Posey LM. Pharmacotherapy: a pathophysiologic approach, vol. 21. 7th ed. New York: The McGraw-hill Companies, Inc.; 2008. p. 331-68.

2. Kamali F, Pirmohamed M. The future prospects of pharmacogenetics in oral anticoagulation therapy. Br J Clin Pharmacol. 2006;61 (6):746-51.

3. Wofford JL, Wells MD, Singh S. Best strategies for patient education about anticoagulation with warfarin: a systematic review. BMC Health Serv Res. 2008;8:40.

4. Pirmohamed M, James S, Meakin S, Green C, Scott AK, Walley TJ, Farrar K, Park BK, Breckenridge AM. Adverse drug reactions as cause of admission to hospital: prospective analysis of 18820 patients. BMJ. 2004;329(7456):15-9.

5. Shrestha S, Sapkota B, Kumpakha A, Acharya U, Sharma R. Evaluation of patients' knowledge on warfarin in outpatient pharmacy of a tertiary care cardiac center. BMC Res Notes. 2015:8:429.

6. Roche NG, Chambers F, Nanra J, Bouchier HD, Young S. Evaluation of patient knowledge regarding anticoagulants. Ir Med J. 2003:96(7):211-3.

7. Kagansky N, Knobler H, Rimon E, Ozer Z, Levy S. Safety of anticoagulation therapy in well-informed older patients. Arch Intern Med. 2004;164(18):2044-50.

8. Tang EOY, Lai CS, Lee KK, Wong RS, Cheng G, Chan TY. Relationship between patients' warfarin knowledge and anticoagulation control. Ann Pharmacother. 2003;37(1):34-9.

9. Ye W, Ming CK, Lai HL, Heng JN, Yu K. Knowledge, satisfaction, and concerns regarding warfarin therapy and their association with warfarin adherence and anticoagulation control. Thromb Res. 2014;133(4):550-4

10. Farooq F, Mujtaba SF. Frequency of achieving target INR in patients with prosthetic heart valves. Pak Heart J. 2012:45(2):121-5.
11. Baker JW, Pierce KL, Ryals CA. INR goal attainment and oral anticoagulation knowledge of patients enrolled in an anticoagulation clinic in a Veterans Affairs medical center. J Manag Care Pharm. 2011;17(2):133-42 (Epub 2011/02/26. eng).

12. Obamiro KO, Chalmers L, Bereznicki LRE. Development and validation of an oral anticoagulation knowledge tool (AKT). PLOS ONE. 2016;11(6):e0158071. https://doi.org/10.1371/journal.pone.0158071.

13. Hu A, Chow C, Dao D, Errett L, Keith M. Factors influencing patient knowledge of warfarin therapy after mechanical heart valve replacement. J Cardiovasc Nurs. 2006;21(3):169-75.

14. McCabe PJ, Schad S, Hampton A, Holland DE. Knowledge and self-management behaviors of patients with recently detected atrial fibrillation. Heart Lung. 2008;37(2):79-90.

15. Pourafkari L, Baghbani-Oskouei A, Taban-Sadeghi M, Salamzadeh V, Ghaffari S, Savadi-Oskouei S, Nader ND. Factors influencing various aspects of patients' knowledge of oral anticoagulation. J Cardiovasc Pharmacol. 2018;71(3):174-9.

16. $\mathrm{Ni} \mathrm{H}$, Nauman D, Burgess D, et al. Factors influencing knowledge of and adherence to self-care among patients with heart failure. Arch Intern Med. 1999:159:1613-9.

17. Shuaib W, Iftikhar H, Alweis R, Shahid H. Warfarin therapy: survey of patients' knowledge of their drug regimen. Malays J Med Sci. 2014;21(4):37-41

18. Ageno W, Gallus AS, Wittkowsky A, Crowther M, Hylek EM, Palareti G. Oral anticoagulant therapy - antithrombotic therapy and prevention of thrombosis, 9th ed: American College of Chest Physicians evidencebased clinical practice guidelines. Chest. 2012;141(2):e44S-88S.

19. Gul S, Ayub M. Prevalence of prescribing pattern of more than one NSAID in Pakistan. J Sci Innov Res. 2014;3(2):148-54

20. Yahaya AM, Hassali MA, Awaisu A, Shafie AA. Factors associated with warfarin therapy knowledge and anticoagulation control among patients attending a warfarin clinic in Malaysia. J Clin Diagn Res. 2009;3:1663-70.

21. Cook-Campbell J, Sefton M. Discharge teaching about warfarin. Home Healthc Nurse J Home Care Hosp Prof. 2010;28(6):366-74.

22. Nasser S, Mullan J, Bajorek B. Challenges of older patients' knowledge about warfarin therapy. J Prim Care Community Health. 2011;3(1):65-74.

23. Guzman CL, Blostein MD, Tabah A, Muladzanov A. Patients' knowledge of anticoagulation and its association with clinical characteristics, INR control and warfarin-related adverse events. Blood. 2013;122(21):1738.

24. Al-Omair SF, Musallam NA, Al-Deghaither NY, Al-Sadoun NA, Bayoumy NM. Compliance with and awareness about long-term oral anticoagulant therapy among Saudi patients in a University Hospital, Riyadh, Saudi Arabia. J Appl Hematol. 2016;7:10-6.

25. Shikdar S, Bhattacharya PT. International Normalized Ratio (INR) [Updated 2019 Mar 25]. In: StatPearls. Treasure Island (FL): StatPearls Publishing; 2019.

26. Khudair IF, Hanssens YI. Evaluation of patients' knowledge on warfarin in outpatient anticoagulation clinics in a teaching hospital in Qatar. Saudi Med J. 2010:3(6):672-7.

\section{Publisher's Note}

Springer Nature remains neutral with regard to jurisdictional claims in published maps and institutional affiliations.

Ready to submit your research? Choose BMC and benefit from:

- fast, convenient online submission

- thorough peer review by experienced researchers in your field

- rapid publication on acceptance

- support for research data, including large and complex data types

- gold Open Access which fosters wider collaboration and increased citations

- maximum visibility for your research: over 100M website views per year

At BMC, research is always in progress.

Learn more biomedcentral.com/submissions 